\title{
Anti-thromboembolic strategies in atrial fibrillation
}

\author{
Giuseppe $\mathrm{Cocco}^{1}$, Philipp Amiet ${ }^{2}$, Paul Jerie ${ }^{1}$ \\ ${ }^{1}$ Cardiology Office, Rheinfelden, Switzerland \\ ${ }^{2}$ Medical Office, Rheinfelden, Switzerland
}

\begin{abstract}
Oral anticoagulation (OAC) is highly effective for stroke prevention in high-risk-patients with atrial fibrillation $(A F)$. AF is also a risk for dementia, and effective OAC reduces the risk of dementia. Up to $30 \%$ of patients with AF have a coronary artery disease and antiplatelets are used to avoid thrombotic complications. Patients with AF often have an acute coronary syndrome (ACS) and undergo a percutaneous intervention with stent-implantation. These patients require a triple therapy, i.e. the combination of OAC with dual-antiplatelet therapy. It is obvious that OAC may induce bleeding with potentially deleterious effects on mortality. Even the occurrence of minor bleeding is problematic.

The review describes available data on used anti-thromboembolic regimens in patients treated with OAC (vitamin K antagonists and non-vitamin K antagonists) who need a triple therapy (i.e. anticoagulation and antiplatelets). Most data are from patients who were treated for an ACS and cannot be directly extrapolated for patients with AF. The impact of used stents and novel $P_{2} Y_{12}$ antagonist-antiplatelets and duration of triple therapy is discussed. Often some high-risk patients with AF would need anticoagulation but cannot be given this therapy because of excessive bleeding risks or contraindicating comorbidities: in these patients left atrial appendage closure with an occluding device can be used as an alternative to anti-thromboembolic therapy.

The unavoidable anti-thromboembolic triple therapy carries a strong potential for bleeding events, which increase mortality. We have many data and several recommendations are offered. Nonetheless, we lack solid data on the best anti-thromboembolic regimen in patients with AF who need anticoagulation and antiplatelets. (Cardiol J 2016; 23, 2: 211-223)
\end{abstract}

Key words: atrial fibrillation, anti-thromboembolic regimens

\section{Introduction}

In high-risk-patients with atrial fibrillation $(\mathrm{AF})$, oral anticoagulation $(\mathrm{OAC})$ is highly effective in reducing stroke by $64 \%$, all-cause mortality by $26 \%$ [1-4] and the risk for dementia [5, 6]. In coronary artery disease (CAD), antiplatelets are effective for reducing thrombotic complications [7]. Almost a third of AF-patients have a CAD, many develop an acute coronary syndrome (ACS) and undergo a percutaneous coronary intervention with stent implantation (PCI-SI). After PCI-SI anticoagulated AF-patients require a triple therapy (TT), i.e. OAC with dual-antiplatelet therapy (DAPT). Indeed, almost $10 \%$ of patients undergoing PCI-SI are on OAC [8]. We review the anti-thromboembolic regimens (ATRs) in these patients.

Address for correspondence: Giuseppe Cocco, MD, Cardiology Office, Marktgasse 10A, CH-4310 Rheinfelden, Switzerland, tel: +00 416183145 55, fax: +00 416183397 56, e-mail: praxis@cocco.ch

Received: 02.11.2015 Accepted: 17.12.2015 
Table 1. Pharmacologic interactions of novel oral anticoagulants (NOACs) with frequently used drugs.

\begin{tabular}{ll}
\hline Dangerous interactions of NOACs with: & \\
\hline Cyclosporine & Especially dabigatran \\
Dronedarone & All NOACs \\
Ketoconazole, itraconazole, voriconazole & Apixaban, dabigatran, rivaroxaban \\
HIV-protease inhibitors & Especially apixaban, dabigatran and rivaroxaban \\
Quinidine & Apixaban, dabigatran, rivaroxaban \\
\hline Possibly dangerous interactions with: & \\
\hline Amiodarone & Apixaban, dabigatran, edoxaban \\
Verapamil & Dabigatran \\
\hline Minor interactions with: & \\
\hline H2-blockers & All NOACs \\
\hline
\end{tabular}

\section{Methodology of our search in the literature}

A review must rely on solid data and be objective, delivering the "state of the art" of the chosen argument. We believe that the reviewers should personalize the data.

We started a goal-oriented search in English with the search engines BioMedSearch.com, Cardiosource, CenterWatch, ClinicalTrials.gov, Cochrane Summaries, Google Scholar, MedWatch and PubMed. We settled a time-window 2005 till 2015 with key words AF and ACS, stent implantation and ATRs, TT, and OAC. This search delivered more than 1 million references. By necessity, we restricted our search to a time window 2010 till 2015 and 'filters' for guidelines and metaanalyses. This search delivered more than 90,000 references. We used plagiarism checker software and found that many papers were from the same authors, even if the authors order was changed or some authors were changed. One might maliciously say that some papers were repeating data in different journals. We selected the most recent papers with large numbers of cases and ended with a total of 400 references. From the abstracts we selected 150 full-text papers. Eighty papers gave the "state of the art" about our review. It is unavoidable that we may have selected same papers by chance.

\section{Risks of oral anticoagulation}

Obviously, OAC may induce bleeding with potentially deleterious effects on mortality $[3,8,9]$. In major bleeding, anemia and hypovolemic shock contribute to mortality mechanically and also by triggering inflammatory responses and ischemic events [1-3]. Even the occurrence of minor bleed- ing is problematic. Indeed, nuisance bleeding was associated with cessation of clopidogrel-therapy in more than $10 \%$ of patients, which in turn resulted in an increased rate of thrombotic complications [10].

For decades vitamin $\mathrm{K}$ antagonists (VKAs), e.g. acenocoumarol, phenprocoumon and warfarin, were used for OAC [1-3, 6, 7]. In recent years direct novel oral anticoagulants (NOACs) have been marketed (at present apixaban, dabigatran, edoxaban and rivaroxaban) and have a positive risk/benefit ratio over VKAs [1-3, 7, 11-14]. The number of patients who are first treated with, or are switched from VKAs to NOACs, is steadily increasing [1-3, 15-18]. Nonetheless, cost of NOACs is high and their use is more problematic than expected [15]. Major bleeding (especially intracerebral hemorrhage) occurs significantly less frequently with NOACs [1-3, 15-18], but gastrointestinal and nasal bleedings are not rare. Dabigatran causes dyspepsia in about $10 \%$ of patients [1-3, 15-17]. NOACs have short half-lives and if patients miss 2 doses they will be unprotected. A recent review has shown that morbid adiposity may reduce the efficacy of NOACs [19]. NOACs have fewer pharmacokinetic/-dynamic interactions than VKAs but they have important interactions with inhibitors of the P-glycoprotein transporter and with several drugs used in cardiology [15-17, 20-22]. Table 1 shows potentially toxic pharmacologic interactions of NOACs.

\section{Might NOACs be better than VKAs in triple therapy?}

It might be hypothesized that replacing in TT VKAs by NOACs would improve the risk/benefit ratio. In common clinical practice it is not rare to see patients who are off-label treated with NOACs in combination with aspirin and either prasugrel 
or ticagrelor (a therapy which is contraindicated in modern guidelines). This use has also been documented in the XANTUS study [18], which has proven that rivaroxaban is also used in patients with severe renal insufficiency (a contraindication), in dosages which are not recommended from the company or in guidelines, and in combination with modern antiplatelets ( $a$ contraindicated therapy).

The direct factor Xa-antagonist, apixaban [23], and the direct thrombin-inhibitor, dabigatran [24] were used to prevent stent-thrombosis after PCI-SI, at doses proven be effective in non-valvular AF, in ACS-patient and in combination with aspirin and clopidogrel. Apixaban and dabigatran cannot be combined at the used doses with DAPT because dabigatran was associated with a higher risk of ACS and both apixaban and dabigatran induced excessive bleeding and had no antiischemic benefit [25, 26]. However, the real world XANTUS study has shown that the direct factor Xa-antagonist rivaroxaban induces less bleeding, especially intracerebral hemorrhage, than VKAs [18]. Indeed rivaroxaban underwent a dose-finding trial in ACS-patients who were treated with antiplatelets and it was proven that this TT with very low doses of rivaroxaban (2.5 $\mathrm{mg}$ bid) and DAPT provided the best effect/risk profile in the thromboembolic prophylaxis [27, 28]. These results were extended and confirmed in the ATLAS ACS 2-TIMI 51 trial [29]: in ACS-patients rivaroxaban $(2.5-\mathrm{mg}$ bid) and DAPT (aspirin + + clopidogrel) lead to a highly significant $1.8 \%$ reduction $(p<0.0001)$ in all-cause mortality, furthermore, rivaroxaban demonstrated an additional protective effect against stent-thrombosis. Because of these encouraging results, the PIONEER trial [30] is testing whether these results can be transferred to AF-patients when TT is needed. At present, the use of NOACs in the TT in AF remains a possible therapy requiring further investigations.

\section{Anti-thromboembolic regimens in AF}

Historical trials have shown that VKAs are partially effective in preventing thromboembolic events after a myocardial infarction (MI) [29]. However, monotherapy with VKAs is therapeutically insufficient in $C A D$ and it is no longer recommended by modern guidelines in patients who undergo PCI-SI [9, 31-36]. On the other hand, DAPT without OAC is less effective than VKAs in reducing thromboembolic complications [9]. TT (VKAs, aspirin + clopidogrel) was found to reduce stent-thrombosis rates to $1 \%$ in the first month and to $1-2 \%$ in the first year [9]. Therefore, modern guidelines recommend DAPT (aspirin + a $\mathrm{P}_{2} \mathrm{Y}_{12^{-}}$ -antagonist) as the most effective strategy to prevent thrombosis in anticoagulated patients who undergo $P C I-S I$. Even if considered dangerous, it is not rare to see patients who are off-label treated with OAC (either VKAs or NOAC) in combination with prasugrel or ticagrelor.

Several studies analyzed the effect of different ATRs in anticoagulated patients. Most studies were retrospective, having the advantage of a shorter duration and allowing large number of cases over a long-time. They are not head to head studies and lack real comparative data.

- A study analyzed data from 478 patients who underwent PCI-SI [37]. Several ATRs were compared: 1) TT, i.e. warfarin + DAPT (aspirin + clopidogrel, $100+75 \mathrm{mg} /$ day), 2) warfarin + aspirin $100 \mathrm{mg} /$ day, 3) warfarin + clopidogrel $75 \mathrm{mg} /$ day, and 4) DAPT (aspirin + clopidogrel) alone. Most results are shown in Table 2. No differences were observed in major bleeding in warfarin + aspirin vs. warfarin + + DAPT $(6.1 \%$ vs. $6.6 \%)$, but patients treated with warfarin + aspirin had a significantly $(\mathrm{p}<0.01)$ higher risk for stent-thrombosis ( $15.2 \%$ vs. $1.9 \%)$ or MI (18.2\% vs $8.5 \%)$, than those on warfarin + + DAPT. Of note, in patients treated with warfarin + + clopidogrel there was no significant difference in the occurrence of stent-thrombosis $(0.0 \%$ vs. $1.9 \%)$ or MI (11.1\% vs. $8.5 \%)$ as compared with patients treated with other ATRs. At 12-month follow-up patients treated with DAPT alone had a significantly higher rate of stroke ( $8.8 \%$ vs. $2.8 \%)$ or stent-thrombosis $(5.9 \%$ vs. $1.9 \%, \mathrm{p}<0.01)$ than those on warfarin + DAPT. In this study the number of patients is insufficient to detect rare events.

- A single-center prospective study analyzed data from $426 \mathrm{AF}$-patients who underwent PCI-SI [38]. TT, i.e. VKAs + DAPT (aspirin $100 \mathrm{mg} /$ day + + clopidogrel $75 \mathrm{mg}$ /day) was compared with DAPT alone. TT was used in $50 \%$ of patients and DAPT alone in $41 \%$. Relevant results are shown in Table 3. Mortality rates were significantly higher $(28 \%$ vs. $18 \%, \mathrm{p}<0.01)$ in patients treated with DAPT alone. Of note, also in this prospective study the number of patients is insufficient to detect rare events. - The ACTIVE W study analyzed data from lowrisk, non-anticoagulated AF-patients with ACS who underwent PCI-SI [39, 40]. Several ATRs were used: 1) TT, i.e. VKAs + DAPT (aspirin + clopidogrel), 2) VKAs + single antiplatelet, or 3) VKAs + + placebo. The median follow-up was 3.6 years. Relevant results are shown in Table 2. Patients treated with VKAs + antiplatelets had significantly $(\mathrm{p}<0.01)$ more major cardiovascular events (MACE) 
Table 2. Triple therapy versus vitamin $\mathrm{K}$ antagonist + aspirin, versus vitamin $\mathrm{K}$ antagonist + clopidogrel, versus dual-anti-platelet therapy.

\begin{tabular}{|c|c|c|c|c|}
\hline $\begin{array}{l}\text { Author/ } \\
\text { /References }\end{array}$ & Design & $\begin{array}{l}\text { No. of } \\
\text { patients }\end{array}$ & $\begin{array}{l}\text { Mean } \\
\text { follow-up }\end{array}$ & Endpoints \\
\hline \multirow[t]{5}{*}{$\begin{array}{l}\text { Karjalainen } \\
\text { et al. [37] }\end{array}$} & \multirow[t]{5}{*}{$\begin{array}{l}\text { Retrospective, } \\
6 \text { studies }\end{array}$} & \multirow[t]{5}{*}{479} & \multirow[t]{5}{*}{12 months } & $\begin{array}{l}\text { Warfarin vs. aspirin and TT similar major bleeding } \\
(6.1,6.6 \%)\end{array}$ \\
\hline & & & & $\begin{array}{l}\text { Warfarin }+ \text { aspirin more stent thrombosis vs. TT } \\
(15.2,1.9 \%)\end{array}$ \\
\hline & & & & Warfarin + aspirin vs. TT more MI $(18.2,8.5 \%)$ \\
\hline & & & & $\begin{array}{l}\text { Warfarin + clopidogrel vs. TT similar stent } \\
\text { thrombosis }(0.0,1.9 \%) \text { and } \mathrm{MI}(11.1,8.5 \%)\end{array}$ \\
\hline & & & & DAPT vs. TT more stent thrombosis $(8.8,2.8 \%)$ \\
\hline \multirow{3}{*}{$\begin{array}{l}\text { Sambola } \\
\text { et al. [38] }\end{array}$} & \multirow{3}{*}{$\begin{array}{l}\text { Prospective, } \\
3 \text { centers }\end{array}$} & \multirow[t]{3}{*}{405} & \multirow[t]{3}{*}{6 months } & DAPT vs. other ATRs more mortality $(28,18 \%)$ \\
\hline & & & & $\begin{array}{l}\text { TT vs. other ATRs more major bleeding }(6.5,4.3 \%) \\
\text { and minor bleeding }(11.2,6.5 \%)\end{array}$ \\
\hline & & & & $\begin{array}{l}\text { TT vs. other ATRs less CVE }(7.9,15.2 \%) \\
\text { and less stent thrombosis }(4.0,8.7 \%)\end{array}$ \\
\hline \multirow{2}{*}{$\begin{array}{l}\text { ACTIVE W } \\
{[39,40]}\end{array}$} & \multirow{2}{*}{$\begin{array}{l}\text { Prospective, } \\
12 \text { centers }\end{array}$} & \multirow[t]{2}{*}{$?$} & \multirow[t]{2}{*}{3.6 years } & VKA + antiplatelets vs. VKA placebo more MACE \\
\hline & & & & $\begin{array}{l}\text { VKA + clopidogrel vs. VKA + placebo less MI but } \\
\text { more major bleeding }\end{array}$ \\
\hline
\end{tabular}

ATR - anti-thromboembolic regimens; CVE — cardiovascular events; DAPT — dual-anti-platelet therapy (aspirin + clopidogrel); MI - myocardial infarction; TT — triple therapy (VKAs + DAPT); VKA — vitamin K antagonist

Table 3. Triple therapy versus dual-anti-platelet therapy.

\begin{tabular}{lllll}
\hline $\begin{array}{l}\text { Author/ } \\
\text { /References }\end{array}$ & Design & $\begin{array}{l}\text { No. of } \\
\text { patients }\end{array}$ & $\begin{array}{l}\text { Mean } \\
\text { follow-up }\end{array}$ & Endpoints \\
\hline $\begin{array}{l}\text { Ruiz-Nodar } \\
\text { et al. [41] }\end{array}$ & $\begin{array}{l}\text { Retrospective, } \\
1 \text { center }\end{array}$ & 479 & 594 days & $\begin{array}{l}\text { DAPT vs. TT higher mortality }(28,18 \%) \\
\text { TT vs. ATR higher major bleeding }(14.9,9 \%) \\
\text { and minor bleeding }(12.6,9 \%)\end{array}$ \\
\hline $\begin{array}{l}\text { Ruiz-Nodar } \\
\text { et al. [42] }\end{array}$ & $\begin{array}{l}\text { Retrospective, } \\
2 \text { centers }\end{array}$ & 604 & 693 days & DAPT vs. TT more MACE $(38.7,2.65 \%)$ \\
\hline
\end{tabular}

ATR - antithrombotic regiments; DAPT — dual-anti-platelet therapy (aspirin + clopidogrel); MACE — major cardiovascular events; $\mathrm{MI}$ - myocardial infarction; TT — triple therapy (VKA + DAPT); VKA — vitamin K antagonist

(6.8\% per year) than those receiving VKAs + + placebo. MI occurred significantly $(\mathrm{p}=0.08)$ less often with VKAs + clopidogrel (115 patients) than with VKAs + placebo (90 patients) but major bleeding occurred significantly $(\mathrm{p}<0.001)$ more often with VKAs + clopidogrel $(251 \mathrm{pa}-$ tients, $2.0 \%$ per year) than with VKAs + placebo (162 patients, $1.3 \%$ per year). Thus, in low-risk AF-patients who underwent PCI-SI, an ATRs with VKAs + antiplatelets reduced the risk of major vascular events, especially stroke, whereas it increased the risk of major hemorrhage. The message is that in low-risk, non-anticoagulated AF-patients who undergo PCI-SI, ATRs with TT and also VKAs + single antiplatelet show a poor efficacy/risk profile.
- A retrospective single-center study [41] analyzed data from 405 anticoagulated patients who underwent PCI-SI. Several ATRs were studied: 1) TT, i.e. VKAs + DAPT (aspirin + clopidogrel, 100 and $75 \mathrm{mg} /$ day); 2) VKAs + single antiplatelet, and 3) DAPT alone. TT was used in $50 \%$ of patients and DAPT alone in $41 \%$. Relevant results are shown in Table 3. TT was more effective than VKAs + aspirin, but VKAs + clopidogrel had a similar efficacy. Bleeding rates were not significantly different between TT and VKAs + single antiplatelet (respectively, $15.5 \%$ and $13.0 \%$ ); however, MACE occurred more frequently in patients treated with VKAs + single-antiplatelet $(15.2 \%)$ as compared with those treated with TT (7.9\%) or DAPT $(1.2 \%)$. Of note, the number of patients is 
small and some data are puzzling. It is difficult to understand why major bleeding rates were slightly higher for DAPT than for TT and the reported stent-thrombosis rate of $15 \%$ is much higher than in most recent trials on PCI-SI. Mortality rates were significantly higher $(28 \%$ vs. $18 \%$, p < 0.01$)$ in patients treated with DAPT alone. Of note, also in this study the number of patients is insufficient to detect rare events.

- A retrospective 2-center study from the same authors [42] analyzed data from 604 AF-patients who underwent PCI-SI. Patients were matched using propensity scores. TT, i.e. VKAs + DAPT (aspirin + clopidogrel, 100 and $75 \mathrm{mg} /$ day) was compared with DAPT alone. Relevant results are shown in Table 3. Bleeding was significantly more frequent with TT than with DAPT. Of note in this study the number of patients was small, the odds ratio, hazard ratio and confidence interval were not reported.

\section{Meta-analyses and registries}

- A meta-analysis of 9 trials [43] assessed the results from 5,181 anticoagulated AF-patients who underwent PCI-SI. TT, i.e. warfarin + DAPT (aspirin + clopidogrel, 100 and $75 \mathrm{mg} /$ day) was compared with DAPT alone. Relevant results are shown in Table 4. The overall incidence of death $(\mathrm{p}=0.56)$ and $\mathrm{MI}(\mathrm{p}=0.38)$ was comparable. However, TT was significantly $(\mathrm{p}=0.0004)$ more effective than DAPT in reducing ischemic stroke, but with a significantly $(\mathrm{p}<0.0001) 2$-fold increased risk of major bleeding. These results are along those from the other trials; TT is significantly more effective than DAPT alone, but carries a significant bleeding risk. - A registry [44] assessed the occurrence of MACE in 118,606 anticoagulated AF-patients who underwent PCI-SI and were treated with either VKAs alone or TT (VKAs + DAPT). Relevant results are shown in Table 4. The overall incidences of death or MI were comparable with all ATRs. However, TT was significantly ( $\mathrm{p}<0.0004)$ more effective in stroke prevention than DAPT alone but carried a significantly ( $\mathrm{p}<0.0001), 2$-fold increased risk of major bleeding. During a mean follow-up of 3.3 years the risk of bleeding was more than 3-fold elevated compared with VKAs monotherapy. Of note, in this registry, patients were not randomized and it is difficult to detect possible differences among the various ATRs.

- A Danish nationwide registry [45] collected data from 11,480 AF-patients with either acute MI $(76.4 \%)$ or after elective PCI-SI $(23.6 \%)$.
A group of $17.3 \%$ of all patients with MI underwent PCI-SI within 1 week, but only $13 \%$ were treated with TT. Results are shown in Table 4. The registry indicates that, although OAC was indicated, not all patients at increased bleeding risk were treated with VKAs + DAPT. Data from this registry show a common therapeutic problem emerging when TT should be used: the fear of the bleeding risks related to TT seems to prevent physicians from referring anticoagulated ACS-patients for a PCI-SI. Thus, in this registry, bleeding in patients treated with TT patients may be underestimated.

- A multinational registry [46] collected data from 9 clinical trials in 1,996 anticoagulated (with VKAs) patients who underwent PCI-SI. Few drug-eluting stents (DES) were used. Patients were discharged either on TT, i.e. VKAs + DAPT (aspirin + clopidogrel, $100 \mathrm{mg}+75 \mathrm{mg} /$ day) or VKAs + single antiplatelet. The ischemic events at a 6-month follow-up were compared. Relevant results are shown in Table 4. Stent-thrombosis rates did not increase excessively when patients were treated with VKAs + single antiplatelet. However, TT was significantly $(\mathrm{p}<0.005)$ more effective to prevent $M A C E$ and even with regard to mortality $(\mathrm{p}<0.01)$, but was accompanied by significantly $(\mathrm{p}<0.04)$ more major bleeding events. These data support those from other studies.

- The CRUSADE registry [47] collected data from 5,673 anticoagulated (with warfarin) AF-patients with a non-ST-elevation-ACS. A group of $1,247(22 \%)$ patients underwent PCI-SI and were discharged on three different ATRs: $60 \%$ on TT, i.e. warfarin + DAPT, $31 \%$ on DAPT (aspirin + + clopidogrel, 100 and $75 \mathrm{mg} /$ day), and $3 \%$ on warfarin + aspirin. Results are shown in Table 4. Warfarin + aspirin was at least as effective as TT (warfarin + DAPT) to prevent coronary ischemic events but was associated with less bleeding complications.

Similar data were reported in the GRACE trial [48, 49]. Eight hundred patients with PCI-SI for ACS were analyzed. One hundred and thirty patients received DES. Patients were discharged on warfarin and either DAPT (580 patients, aspirin + + either clopidogrel or ticlopidine) or single antiplatelet therapy (220 patients). Data are shown in Table 4 . The use of warfarin + single antiplatelet therapy was more common in Europe than in the United States (34\% vs. $17 \%$, p < 0.001). There was no difference in major bleeding in hospital or in 6 -month mortality or MI. In the single antiplatelet group, the use of either aspirin or thienopyridine 
Table 4. Meta-analyses and registries (TT, VKA and DAPT).

\begin{tabular}{|c|c|c|c|}
\hline Author/References & Design & $\begin{array}{l}\text { No. of } \\
\text { patients }\end{array}$ & Endpoints \\
\hline \multirow[t]{2}{*}{ Gao et al. [43] } & \multirow{2}{*}{$\begin{array}{l}\text { Meta-analysis, } \\
9 \text { trials }\end{array}$} & \multirow[t]{2}{*}{5,181} & TT vs. DAPT similar death and MI \\
\hline & & & TT vs. DAPT less strokes but 2-fold more major bleeding \\
\hline \multirow[t]{2}{*}{ Hensen et al. [44] } & \multirow[t]{2}{*}{ Registry } & \multirow[t]{2}{*}{118,606} & TT and VKA + SA and DAPT similar death and MI \\
\hline & & & $\begin{array}{l}\text { TT vs. DAPT better stroke prevention but 2-fold more } \\
\text { major bleeding }\end{array}$ \\
\hline Lamberts et al. [45] & Registry & 11,480 & $\begin{array}{l}\text { After } \mathrm{PCl}-\mathrm{SI} \text { only } 13 \% \text { of atrial fibrillation-patients } \\
\text { received TT }\end{array}$ \\
\hline \multirow[t]{2}{*}{ Zhao et al. [46] } & \multirow{2}{*}{$\begin{array}{l}\text { Registry, } \\
9 \text { trials }\end{array}$} & \multirow[t]{2}{*}{1,196} & VKA + SA vs. TT similar stent thrombosis \\
\hline & & & $\begin{array}{l}\text { TT vs. VKA + SA less MACE and less mortality but } \\
\text { more major bleeding }\end{array}$ \\
\hline \multirow[t]{2}{*}{ CRUSADE [47] } & \multirow[t]{2}{*}{ Registry } & \multirow[t]{2}{*}{5,673} & $\begin{array}{l}\text { TT and VKA + aspirin same reduction in coronary } \\
\text { ischemic events }\end{array}$ \\
\hline & & & TT vs. VKA + SA more major bleeding \\
\hline GRACE $[48,49]$ & Registry & 800 & $\begin{array}{l}\text { Warfarin + clopidogrel or ticlopidine has similar mortality } \\
\text { and } \mathrm{MI}\end{array}$ \\
\hline
\end{tabular}

DAPT — dual-anti-platelet therapy (aspirin + clopidogrel); MACE - major cardiovascular events; $\mathrm{MI}$ - myocardial infarction; PCl-SI - percutaneous coronary intervention with stent implantation; TT — triple therapy (VKA + DAPT); VKA — vitamin K antagonist; SA — single antiplatelet

(clopidogrel or ticlopidine) in combination with warfarin resulted in similar outcomes.

Data from the last two registries differ from other studies and support the knowledge that stentthrombosis rates do not increase excessively when patients are treated VKAs + single antiplatelet in comparison to TT. Of note, in these registries, the number of patients who received a DES is insufficient to draw final conclusions.

Finally, in the LAST trial [50] with the stents used till 2005, the ATR with VKAs + aspirin was less effective than TT to prevent stent thrombosis.

Comparing the above trials is problematic. Most studies were retrospective and observational, the number of patients is too low to draw conclusive information, selected patients were different and the definition of bleeding was not the same. In 2014, the Bleeding Academic Research Consortium offered a new definition but we are still looking for an acceptable definition of major bleeding [51]. However, it can be considered proven that anticoagulated AF-patients who undergo PCI-SI have significantly more MACE when they are not discharged on TT, but that TT clearly carries an increased risk for bleeding. Thus, in AF-patients who need TT we are still looking for an ATRs with good protection from thromboembolic events without high bleeding risks.

\section{Duration of triple therapy}

- The randomized, open-label trial ISAR-TRIPLE trial $[52,53]$ was performed in 3 European centers and involved 614 patients. Anticoagulated patients who underwent PCI-SI (with DES) received a TT, i.e. VKAs + DAPT (aspirin + clopidogrel). The primary endpoint was a composite of death, MI, definite stent-thrombosis, stroke, or major bleeding. The effects of a 6 -week vs. 6 -month TT-duration were compared. Results are shown in Table 5. The primary endpoint occurred in $30(9.8 \%)$ patients in the 6 -week arm compared with $27(8.8 \%)$ patients 6 -month arm $(\mathrm{p}=0.63)$. There were no significant differences for the secondary combined ischemic endpoint of cardiac death, MI, definite stent-thrombosis and ischemic stroke $(p=0.87)$, or the secondary bleeding endpoint of thrombolysis in myocardial infarction (TIMI) major bleeding $(\mathrm{p}=0.44)$. Thus net clinical outcomes were similar with a 6-week and a 6-month TT. These results suggest that physicians should weigh the trade-off between ischemic and bleeding risk when choosing the shorter or longer duration of TT.

- The prospective, multicenter, open-label, randomized WOEST trial [54] was performed in $15 \mathrm{Bel}-$ gian and Dutch hospitals. A group of 573 patients who were anticoagulated with VKAs for at least 
Table 5. Duration of triple therapy (TT).

\begin{tabular}{llll}
\hline Author/References & Design & $\begin{array}{l}\text { No. of } \\
\text { patients }\end{array}$ & Endpoints \\
\hline ISAR-TRIPLE [52,53] & $\begin{array}{l}\text { Randomized, } \\
\text { open-label }\end{array}$ & 614 & $\begin{array}{l}\text { 6-week vs. 6-month TT: death was similar }(9.8 \% \text { vs. } \\
8.8 \%) \text {, also similar, MI, stent thrombosis, ischemic } \\
\text { stroke and TIMI major bleeding }\end{array}$ \\
\hline WOEST [54] & $\begin{array}{l}\text { Randomized, } \\
\text { multicenter, }\end{array}$ & 573 & $\begin{array}{l}\text { VKA + single antiplatelet vs. TT: significantly less minor } \\
\text { bleeding and major bleeding (19.5 vs. 44.9\%), also less } \\
\text { frequent MI, stroke, stent thrombosis and intracranial } \\
\text { bleeding }\end{array}$ \\
\hline
\end{tabular}

$\mathrm{MI}$ - myocardial infarction; TIMI — thrombolysis in myocardial infarction; VKA — vitamin $\mathrm{K}$ antagonist

1 year and were scheduled for PCI-SI were randomized to different ATRs: 1) TT, i.e. VKAs + DAPT (aspirin + clopidogrel, 80 and $75 \mathrm{mg} /$ day), 2) VKAs + + aspirin $80 \mathrm{mg} /$ day, and 3) VKAs + clopidogrel $75 \mathrm{mg} /$ day. The ATRs was continued for 1 month after bare-metal stent (BMS) implantation (35\% of patients), or for 1 year after DES-implantation (65\% of patients). Follow-up time was 1 year. The primary endpoint of all types of TIMI minimal, minor and major bleeding was significantly $(\mathrm{p}<$ $<0.001$ ) reduced in the VKAs + single antiplatelet vs. TT (19.5\% vs. $44.9 \%)$. Minimal bleedings were also significantly reduced, while major bleeding events were numerically lower but did not reach statistical significance. Intracranial bleeding was unchanged. Although the trial was not powered for the analysis of ischemic events, it is interesting to note that MI, stroke, and stent-thrombosis were numerically lower and mortality was significantly lower in VKAs + single antiplatelet.

Concluding, we have many data but at present the best duration and type of ATRs in AF-patients who undergo PCI-SI is unknown. The available information can be considered hypothesis-generating.

\section{Third-generation $\mathrm{P}_{2} \mathrm{Y}_{12}$ antagonists}

In AF-patients who undergo PCI-SI, the occurrence of stent-thrombosis is substantially increased if TT is not used and most published data have shown that monotherapy with DAPT (aspirin + clopidogrel) has tested inferior compared with VKAs to reduce thromboembolic events [1-3, 9, 15, 54-59]. In ACS-patients who undergo PCI-SI, anti-thromboembolic monotherapy with VKAs is not an alternative to DAPT therapy. Thus, the current standard of secondary prevention of atherothrombotic events in these patients includes a TT, i.e. OAC in combination with DAPT with aspirin and a $\mathrm{P}_{2} \mathrm{Y}_{12}$ receptor-antagonist. Compared with clopidogrel and ticlopidine, the third-generation $\mathrm{P}_{2} \mathrm{Y}_{12}$ receptor-antagonists (at present cangrelor, prasugrel and ticagrelor) provide faster, stronger, and more reliable antiplatelet activity [31-36].

The 2015 updated European Society of Cardiology (ESC) guidelines [36] recommend that ACS-patients should be divided into four groups: very-high-risk, high-risk, middle-risk and low-risk. This stratification should be used to choose a specific type of interventional and medical. In the 2015 ESC guidelines [36], prasugrel and ticagrelor have class I recommendations for the treatment of ACS and there is a class II indication for the recently approved cangrelor. Based on the TRITON-TIMI 38 [60, 61] and PLATO [62] trials, the guidelines recommend a 12-month DAPT with new DES. In selected cases the duration of DAPT could be longer than 12 months, for clopidogrel or prasugrel up to 30 months [60-64], for ticagrelor up to 48 months $[61,62,65]$. However, because of observed bleeding complications it is recommend not using prasugrel prior to PCI-SI [60-64]. The PEGASUS-TIMI 54 trial [cited in 36] suggests that the superior anti-thromboembolic efficacy of DAPT with aspirin + ticagrelor comes at cost of increased bleeding events. In the observational TRITON-TIMI 38 trial $[60,61]$, prasugrel was compared with clopidogrel in DAPT: minor and major bleeding occurred significantly $(p<0.03)$ more often with prasugrel than with clopidogrel and no significant difference in ischemic endpoints was observed. Thus, we know that ticagrelor and prasugrel are more effective in ACS but cause more bleeding than clopidogrel. Another aspect of $\mathrm{P}_{2} \mathrm{Y}_{12}$ receptor-antagonists is unrelated to bleeding risks. The TRILOGY trial [65] reported higher rates of cancer-related death among patients receiving either $60 \mathrm{mg} /$ day or $90 \mathrm{mg} /$ day ticagrelor than among those receiving placebo $(1.10 \%$ and $0.92 \%$ vs. $0.76 \%$ ). A Food and Drug Association (FDA)-review reported the association between 
bleeding and solid cancers with prasugrel [66] and another FDA review on DAPT [67] documented that the relative risk of the incidence of solid tumors was about $1.2 \%$ with clopidogrel and $1.3 \%$ with prasugrel, as compared with placebo. However, the FDA reviewed the data concluding that causality of cancer was unlikely and the chance of a false positive finding was high [68]. This conclusion was also supported by the prospective assessment of cancer in the TRILOGY trial [65], which showed no excess of cancers with ticagrelor $90 \mathrm{mg}$ of ticagrelor as in in the PLATO trial with clopidogrel [62].

Of note, the ESC recommendations are only valid for non-ST-elevation-ACS-patients who are not anticoagulated. At present we ignore whether, in anticoagulated AF-patients who undergo PCI-SI and need TT replacing clopidogrel with either ticagrelor or prasugrel would be safe and more effective. As already mentioned, in common practice it is not rare to find patients who are anticoagulated (with either VKAs or NOACs) and who are off-label treated with aspirin + either ticagrelor or prasugrel.

The American College of Chest Physicians/ /American Heart Association (ACCF/AHA) guidelines on ATRs for AF-patients recommend the use of TT, i.e. VKAs + DAPT (aspirin $+\mathrm{a} \mathrm{P}_{2} \mathrm{Y}_{12}$-antagonist) for thromboembolic prophylaxis [9]. The duration of TT ranges from 1 month when BMS were used, and to 3 months, 6 months up to 12 months depending on the DES-type. For anticoagulated patients who undergo PCI-SI, both the $2012 \mathrm{ACCF} /$ /AHA guidelines [9] and the 2012 ESC guidelines [34] gave similar recommendations: 2-4-weekthrough 6-month-TT depending on the individual bleeding risk, type of DES, and circumstances (ACS or elective) of DES-implantation. In anticoagulated AF-patients who undergo PCI-SI, DAPT should be stopped after 12 months and OAC-monotherapy (either VKAs or NOACs) should be continued for long-term thromboembolic prevention.

Of note, in all guidelines these recommendations are only for ACS patients who underwent PCI-SI and not based on randomized trials. A major difference between the United States and ESC guidelines is the recommended international normalized ratio (INR) in the combination of VKAs + DAPT. The 2012 ESC guidelines [34] recommend maintaining a reduced INR 2.0-2.5, whereas the $2012 \mathrm{ACCF} /$ /AHA guidelines [9] recommend an INR of 2.0-3.0. There is a great uncertainty about the best type and duration of the TT in AF-patients. Published data are in favor of limiting the duration of TT to the early phase and to continue with VKAs + single antiplatelet later on.
At the 2015 ESC congress [36] new data were presented on anti-thromboembolic therapy with antiplatelets. The BASKET-PROVE-II study [69] has shown that DAPT with aspirin + prasugrel is effective and safe in patients with stable $C A D$ and that in ACS-patients it has a similar bleeding risk as a DAPT with aspirin + clopidogrel. The ATLANTIS-H24 study [cited in 36] has shown that it is useful to administer ticagrelor in the first $24 \mathrm{~h}$ of occurrence of ACS. In the 2015 ESC Congress, meta-analysis data from randomized controlled studies were presented and it was confirmed that the present knowledge is insufficient to decide about the optimal duration of DAPT after PCI-SI [36]. After PCI-SI, DAPT was significantly more effective (HR 0.78; 0.67-0.90; $p=0.001$ ) than a 1-year therapy with monotherapy with aspirin in reducing MI, strokes and cardiovascular death, but this positive effect was accompanied by a significant increase for major bleeding, whereas deadly and intracranial bleeding complications were similar with DAPT and aspirin alone. However, the positive effect of DAPT on MACE was not statically significant in all analyzed studies. It is concluded that patients with high ischemic burden and low bleeding risk take advantage from long DAPT. Of note, these recommendations apply to ACS-patients who are not anticoagulated and should not be extrapolated to other cardiac pathologies.

In conclusion, at present we have insufficient information on the best ATR in AF-patients who undergo PCI-SI with newer DES. In the ISAR-TRIPLE trial $[52,53]$, a 6 -week TT was not inferior to a 6-month-TT with respect to net clinical outcomes. Most trials [40-49, 58, 59] also suggest that an ATRs with VKAs + a single $\mathrm{P}_{2} \mathrm{Y}_{12}$-antagonist might be sufficient to prevent stent-thrombosis and that it induces less bleeding than a VKAs + DAPT. In any case, under TT the INR should be maintained at a lower target range of 2.0-2.5 instead of 2.0-3.0 and aspirin and clopidogrel should be given in the usual doses as recommended for stent implantation.

\section{Impact of the type of coronary stents on thrombotic risk}

After implantation the type of stent is of critical importance for the duration of the ATRs. The risk of stent-thrombosis is highest early after implantation while the risk of bleeding stays at similar levels after the very initial invasive phase $[9,40-49,58,59]$. The time until the BMS-struts are covered by endothelium is considered to last 4 weeks and consequently DAPT is required only for this time period [9, 40-49, 58, 59]. For 
DES-implantation modern guidelines recommend a 3-month DAPT in the case of implantation of an mTOR-inhibitor-eluting-stent, and a 6-month, up to 1-year DAPT in the case of implantation of a paclitaxel-DES [9, 40-49, 58, 59, 69-72]. The retrospective ATLAS ACS 2-TIMI trial [29] compared the outcomes of anticoagulated patients undergoing PCI-SI with either BMS or DES. The incidence of ischemic events and all-cause mortality were similar, but DES-implantation was associated with a significantly increased risk of major bleeding in the follow-up period. Thus, when there is the necessity to reduce the duration of TT, BMS might be the preferred stent-type for patients who need a short duration of TT [29]. The situation is different in patients who were treated for stent-thrombosis after PCI-SI: special emphasis is on prevention of recurrent stent-thrombosis rather than on reducing bleeding risk and TT should be maintained for longer periods [9, 40-49, 58, 59, 69-72]. Recent data have shown that with newer DES extended duration of DAPT may be unnecessary and less beneficial as with earlier DES [9, 41-49, 58, 59, 70-73]. Indeed, some recent DES types have obtained clinical approval for only 3 months of DAPT [74].

At present, the duration of DAPT after PCI-SI with new DES is under critical discussion. It is important to solve the problems related to the best type and duration of ATRs in patients who need $\mathrm{OAC}+$ antiplatelets. Most groups recommend continuing TT for 3-6 months, depending on the type of DES and bleeding risk of the patient. However, it is questionable whether shorter periods of TT would also be effective and safer. It is still unproven, but it might be, that third-generation 'olimus'-eluting-stents require a shorter duration of TT. In a large clinical trial, in patients receiving new generation DES-zotarolimus [40, 49, 52-59], no differences were observed between a 3-month DAPT vs. a 12 -month DAPT. To answer at least some of the missing information, the MUSICA interventional trial [38] is currently enrolling more than 2,300 patients who will be assigned to receive TT or DAPT: the primary endpoint is the occurrence of ischemia, and the secondary endpoint consists of bleeding complications.

\section{Can triple therapy be individualized in AF-patients?}

The goal should be to reduce bleeding events while maintaining anti-thromboembolic effectiveness. In one study, clinical and echocardiographic criteria were used to decide which the best ATRs is for patients who undergo PCI-SI [53]. DAPT (aspirin + clopidogrel) was compared with TT, i.e. VKAs + DAPT (aspirin + clopidogrel). At 2-year follow-up no significant differences in terms of MACE were observed between DAPT or TT, suggesting that this approach may be useful to balance risks and benefits. However, not all anticoagulated patients had $A F$ and thus we ignore if these data are also valid for AF-patients who need TT.

In another study, anticoagulated (with VKAs) AF-patient who needed PCI-SI were grouped according to their bleeding risk which was assessed by the HAS-BLED score [75]. More than 70\% of patients had a score of 3 or higher. Remarkably, even in patients with a high bleeding risk, although bleeding rates were higher, the use of ATRs using VKAs were associated with a reduced death rate. Of note, in the real-world XANTUS study, the use of rivaroxaban was also associated with a reduced death rate [18].

Summing up, as confirmed by the data from the 2015 ESC congress [36], the available nonrandomized, mostly retrospective data suggest that TT is more effective than DAPT, or VKAs + + a single antiplatelet but at the expense of increased bleeding rates: when compared with DAPT (aspirin + $+a P_{2} Y_{12}$-antagonist) the bleeding risk is increased by about 2-5-fold by TT [34, 35, 52-54]. Therefore, as suggested from the ISAR-TRIPLE trial [52, 53], it is wise to keep the duration of TT as short as possible. Unfortunately, because of their design and size, available studies do not provide final conclusions. Larger and specifically panned trials are needed to test the hypothesis that individualized therapy can optimize the net clinical data on TT.

\section{Occlusion of the left atrial appendage}

Some high-risk AF-patients would need OAC but cannot be given this therapy because of excessive bleeding risks or contraindicating comorbidities [76-78]. Thromboembolic events originate from the left atrium, and therefore, in selected high-risk AF-patients with a contraindication for OAC left atrial appendage closure with an occluding device can be used [76-78]. The technique is not without complications but is quite effective in reducing thromboembolic events in $\mathrm{AF}[78,79]$ and should be considered as an alternative to $\mathrm{OAC}$ and TT in some high risk AF-patients.

\section{General conclusions}

Many AF-patients have CAD develop an ACS and need a PCI-SI. High-risk AF-patients need 
OAC for prevention of thromboembolic events, and DAPT for prevention of stent-thrombosis. The unavoidable TT $(\mathrm{OAC}+\mathrm{DAPT})$ carries a strong potential for bleeding events, which might increase mortality. Based on available data some strategies can be recommended:

- BMS should be preferred for anticoagulated AF-patients who undergo PCI-SI when there is a high bleeding risk or if a major surgery is expected in the next 6 months. After BMS-use, TT should be maintained for 1 month and can be followed by monotherapy with OAC (either NOACs, or VKAs with an INR 2-2.5) or a combined therapy with VKAs and aspirin $80-100 \mathrm{mg} /$ day.

- In anticoagulated AF-patients treated with DES the duration of TT (VKAs + DAPT) should be kept as short as possible to reduce the bleeding risk. The newest DES should be preferred because in comparison to previously used DES the need for long-term DAPT is reduced. In AF-patients with low- to intermediate-bleeding risk most guidelines recommend a TT-duration for up to 6 months. Recent data from the WOEST trial [54] suggest that in these patients VKAs + clopidogrel $75 \mathrm{mg}$ /day may suffice and that the addition of aspirin might be unnecessary. The validity of the data from WOEST trial [54] is not undiscussed and it might be questioned if aspirin should be abandoned. In this case, the duration of TT, i.e. VKAs + DAPT (aspirin + clopidogrel), should be shortened to 1 month. It should not be forgotten that AF-patients who receive a PCI-SI have an elevated bleeding risk and this argument further supports the notion to reduce TT to 1 month.

- After DES-implantation, when the duration of TT comes to the end, VKAs + clopidogrel should be continued for a total of 1 year. NOACs are offlabel used but are not officially recommended for this indication.

- During a therapy with VKAs + DAPT it is important to target INR to an INR 2.0-2.5 (lower than 3), especially during the combination of VKAs $+\mathrm{a} \mathrm{P}_{2} \mathrm{Y}_{12}$-antagonist. Frequent controls are usually necessary to maintain the INR within this therapeutic range. After completion of TT, OAC for AF (either NOACs or VKAs, INR 2-3) can be continued as usual.

- It should be recalled that in the ACTIVE W study $[39,40]$ low-risk, non-anticoagulated AF-patients who underwent PCI-SI and were treated with TT had significantly more MACE when treated with VKAs + DAPT than with VKAs + placebo. Also, the occurrence of MI and major bleeding was significantly more frequent in patients receiving
VKAs + clopidogrel than in those receiving VKAs + + placebo. Thus, in low-risk AF-patients who undergo PCI-SI, ATRs with either TT or VKAs + clopidogrel reduce the risk of major vascular events, especially stroke, but increase the risk of major hemorrhage. - In AF-patients who need a TT, at present thirdgeneration $\mathrm{P}_{2} \mathrm{Y}_{12}$ antagonists are not recommended because the bleeding risk may be unforeseeably high. Nonetheless, clinical experience shows that some patients are off-label treated with this combination against the recommended guidelines. Further trials are needed for ATRs with the thirdgeneration $\mathrm{P}_{2} \mathrm{Y}_{12}$ antagonists.

- The use of NOACs instead of VKAs for TT is currently not recommended. If, nonetheless, the physician decides to use NOACs for TT, rivaroxaban in a very low dose (2.5-mg bid) may be considered. The PIONEER trial [28] will test if this TT is effective and safe in AF-patients. However, currently only an extrapolation from scarce existing data is available to support the use of NOACS for TT in AF-patients.

- With TT (VKAs + DAPT) and also with VKAs + + a single antiplatelet patients should be treated with a proton pump inhibitor to reduce the risk of gastrointestinal bleeding. Obviously, drugs increasing the risk, such as non-steroidal antiinflammatory drugs should be avoided.

- In high-risk AF patients with a high risk for bleeding occlusion of the left atrial appendage might be a valuable option to avoid OAC.

\section{Acknowledgement}

We thank Mrs. J. Bugmann for her help and typewriting of the manuscript.

Conflict of interest: None declared

\section{References}

1. Camm AJ, Lip GYH, De Caterina R et al. Focused update of the ESC Guidelines for the management of atrial fibrillation. Eur Heart J, 2012; 33: 2719-2747. doi: 10.1093/eurheartj/ehs253.

2. Pillarisetti J, Lakkireddy D. Atrial fibrillation in Europe: State of the state in disease management. Eur Heart J, 2014; 35 : 3326-3327. doi:10.1093/eurheartj/ehu415.

3. Cocco G, Jerie P. New concepts in the therapy of atrial fibrillation. Cardiol J, 2016; 23: 3-11. doi: 10.5603/CJ.a2015.0053.

4. Lipp GYH. The CHA2DS2-VASc score for stroke risk stratification in patients with atrial fibrillation: A brief history. Eur Heart J, 2015; 36: 2880-2885.

5. Roten L. Subklinisches Vorhofflimmern. info@herz+gefäss, 2015; 4: 8-10.

6. Dürst U, Riesen WF. Vorhofflimern aus Ursache für Demenz? info@herz+gefäss, 2015; 4: 11-13. 
7. Kirchhof P, Auricchio A, Bax J et al. Outcome parameters for trials in atrial fibrillation: Recommendations from a consensus conference organized by the German Atrial Fibrillation Competence NETwork and the European Heart Rhythm Association. Europace, 2007; 9: 1006-1023.

8. Yusuf S, Mehta SR, Chrolavicius S et al. Effects of fondaparinux on mortality and reinfarction in patients with acute ST-segment elevation myocardial infarction: The OASIS-6 randomized trial. JAMA, 2006; 295: 1519-1530.

9. O'Gara PT, Kushner FG, Ascheim DD et al. American College of Cardiology Foundation/American Heart Association Task Force on Practice G. 2013 ACCF/AHA guideline for the management of ST-elevation myocardial infarction: A report of the American College of Cardiology Foundation/American Heart Association Task Force on Practice Guidelines. Circulation, 2013; 127: e362-e425.

10. Roy P, Bonello L, Torguson R et al. Impact of 'nuisance' bleeding on clopidogrel compliance in patients undergoing intracoronary drug-eluting stent implantation. Am J Cardiol, 2008; 102: 1614-1617.

11. Connolly SJ, Ezekowitz MD, Yusuf S et al. Dabigatran versus warfarin in patients with atrial fibrillation. N Engl J Med, 2009; 361: 1139-1151.

12. Granger $\mathrm{CB}$, Alexander JH, McMurray A et al. Apixaban versus warfarin in patients with atrial fibrillation. N Engl J Med, 2011; 365: 981-992.

13. Patel MR, Mahaffey KW, Garg J et al. Rivaroxaban versus warfarin in nonvalvular atrial fibrillation. N Engl J Med, 2011; 365: 883-891.

14. Moser M, Olivier CB, Bode C. Triple antithrombotic therapy in cardiac patients: More questions than answers. Eur Heart J, 2014; 35: 216-223. doi: 10.1093/eurheartj/eht461.

15. Shurlock B. New oral anticoagulants for non-valvular atrial fibrillation: Harder to handle than expected? Eur Heart J, 2014; 35: 1825-1830.

16. Bas H. Neu Antikoagulantien in der Praxis. Ars Med, 2014; 4 : 14-18.

17. Bonetti N, Laube ES, Beer JH. NOACs: "NO Anticoagulant without Consideration". Cardiovasc Med, 2014; 17: 213-220.

18. Camm AJ, Amarenco P, Haas S et al. XATUS: A real-world, prospective, observational study of patients treated with rivaroxaban for stroke prevention in atrial fibrillation. Eur Heart J, 2015 Sep 1. pii: ehv466. [Epub ahead of print].

19. Domienik-Karłoiwcz J, Pruszczyk P. The use of anticoagulants in morbidly obesity patients. Cardiol J, 2016; 23: 12-16. doi: 10.5603/CJ.a2015.0054.

20. Conen D. Edoxaban and amiodarone: Interactions on multiple levels. Eur Heart J, 2015; 36: 2210-2211. doi: 10.1093/eurheartj/ ehv245.

21. Mohrien K, Oliphan CS, Self TH. Drug interactions with novel oral anticoagulants. Consultant, 2013; 53: 918-919.

22. Altena R, van Roon E, Folkeringa R et al. Clinical challenges related to novel oral anticoagulants: Drug-drug interactions and monitoring. Haematologica, 2014; 99: e26-e27. doi: 10.3324/ haematol.2013.097287.

23. Alexander JH, Lopes RD, James S et al. Apixaban with antiplatelet therapy after acute coronary syndrome. N Engl J Med, 2011; 365: 699-698.

24. Oldgren J, Budaj A, Granger CB et al. Dabigatran vs. placebo in patients with acute coronary syndromes on dual antiplatelet therapy: A randomized, double-blind, phase II trial. Eur Heart J, 2011; 32: 2781-2789.

25. Uchino K, Hernandez AV. Dabigatran associated with higher risk of acute coronary events: Meta-analysis of non inferiority randomized controlled trial. Arch Intern Med, 2012; 5: 397-302; doi: 10.1001/archinternmed.2011.1666.

26. Oldgren J, Wallentin L, Alexander JH et al. New oral anticoagulants in addition to single or dual antiplatelet therapy after an acute coronary syndrome: A systematic review and metaanalysis. Eur Heart J, 2013; 34: 1670-1680.

27. Mega JL, Braunwald E, Mohanavelu S et al. Rivaroxaban versus placebo in patients with acute coronary syndromes (ATLAS ACSTIMI 46): A randomised, double-blind, phase II trial. Lancet, 2009; 374: 29-38.

28. Mega JL, Braunwald E, Wiviott SD et al. Rivaroxaban in patients with a recent acute coronary syndrome. N Engl J Med, 2012; 366: 9-19.

29. Krantz MJ, Kaul S. The ATLAS ACS 2-TIMI 51 trial and the burden of missing data: Anti-Xa Therapy to Lower Cardiovascular Events in Addition to Standard Therapy in Subjects With Acute Coronary Syndrome ACS 2-Thrombolysis In Myocardial Infarction. J Am Coll Cardiol, 2013; 27: 777-778. doi: 10.1016/j. jacc.2013.05.024.

30. http://www.anticoagulant-trials.eu/studies-a-z/detail/study/pioneer-af-PCI-SI.html.

31. Lip GY, Huber K, Andreotti F, Arnesen H et al. Antithrombotic management of atrial fibrillation patients presenting with acute coronary syndrome and/or undergoing coronary stenting: Executive summary: A Consensus Document of the European Society of Cardiology Working Group on Thrombosis, endorsed by the European Heart Rhythm Association (EHRA) and the European Association of Percutaneous Cardiovascular Interventions (EAPCI-SI). Eur Heart J, 2010; 31: 1311-1318.

32. Wijns W, Kolh P, Danchin N et al. Guidelines on myocardial revascularization: The task force on myocardial revascularization of the European Society of Cardiology (ESC) and the European Association for Cardio-Thoracic Surgery (EACTS). Eur Heart J, 2010; 31: 2501-2555.

33. Hamm CW, Bassand JP, Agewall S, Bax J et al. ESC Guidelines for the management of acute coronary syndromes in patients presenting without persistent ST-segment elevation: The task force for the management of acute coronary syndromes (ACS) in patients presenting without persistent ST-segment elevation of the European Society of Cardiology (ESC). Eur Heart J, 2011; 32: 2999-3054. doi: 10.1016/j.jacc.2015.02.050.

34. Steg PG, James SK, Atar D et al. ESC Guidelines for the management of acute myocardial infarction in patients presenting with ST-segment elevation: The Task Force on the management of ST-segment elevation acute myocardial infarction of the European Society of Cardiology (ESC). Eur Heart J, 2012; 33: 2569-2619.

35. You JJ, Singer De, Howard PA et al. Antithrombotic therapy for atrial fibrillation: Antithrombotic therapy and prevention of thrombosis. $9^{\text {th }}$ Ed. Am Coll Chest Physicians Evidence-based Clinical Practice Guidelines. Chest, 2012; 141: e-531S-575S.

36. Learning Opinions. ESC Congress London 2015; ISSN 24123269/LO Kongress Kompakt, p. 3-6.

37. Karjalainen PP, Porela P, Ylitalo A et al. Safety and efficacy of combined antiplatelet warfarin therapy after coronary stenting. Eur Heart J, 2007; 28: 726-732.

38. Sambola A, Ferreira-Gonzalez I et al. Therapeutic strategies after coronary stenting in chronically anticoagulated patients: The MUSICA study. Heart, 2009; 95: 1483-1488.

39. Connolly SJ, Yusuf S, Camm, S. Chrolavicius et al. The ACTIVE investigators. Effect of clopidogrel added to aspirin in patients with atrial fibrillation. N Engl J Med, 2009; 360: 2066-2078. doi: 10.1056/NEJMoa0901301. 
40. Dewilde WJ, Oirbans T, Verheugt FW et al. Use of clopidogrel with or without aspirin in patients taking oral anticoagulant therapy and undergoing percutaneous coronary intervention: An open label, randomised, controlled trial. Lancet, 2013; 381: 1107-1115.

41. Ruiz-Nodar JM, Marin F, Hurtado JA et al. Anticoagulant and antiplatelet therapy use in 426 patients with atrial fibrillation undergoing percutaneous coronary intervention and stent implantation implications for bleeding risk and prognosis. J Am Coll Cardiol, 2008; 51: 818-825.

42. Ruiz-Nodar JM, Marin F, Sanchez-Paya J et al. Efficacy and safety of drug-eluting stent use in patients with atrial fibrillation. Eur Heart J, 2009; 30: 932-939.

43. Gao F, Zhou YJ, Wang ZJ, Yang SW et al. Meta-analysis of the combination of warfarin and dual antiplatelet therapy after coronary stenting in patients with indications for chronic oral anticoagulation. Int J Cardiol, 2011; 148: 96-101.

44. Hensen ML, Sorensen R, Clausen MT et al. Risk of bleeding with single, dual, or triple therapy with warfarin, aspirin, and clopidogrel in patients with atrial fibrillation. Arch Intern Med, 2010; 170: 1433-1441.

45. Lamberts M, Olesen JB, Ruwald MH et al. Bleeding after initiation of multiple antithrombotic drugs, including triple therapy, in atrial fibrillation patients following myocardial infarction and coronary intervention: A nationwide cohort study. Circulation, 2012; 126: 1185-1193.

46. Zhao HJ, Zheng ZT, Wang ZH et al. 'Triple therapy' rather than 'triple threat': A meta-analysis of the two antithrombotic regimens after stent implantation in patients receiving long-term oral anticoagulant treatment. Chest, 2011; 139: 260-270.

47. Wang TY, Robinson LA, Ou FS et al. Discharge antithrombotic strategies among patients with acute coronary syndrome previously on warfarin anticoagulation: Physician practice in the CRUSADE registry. Am Heart J, 2008; 155: 361-368.

48. Nguyen MC, Lim YL, Walton A et al. GRACE. Combining warfarin and antiplatelet therapy after coronary stenting in the global registry of acute coronary events: Is it safe and effective to use just one antiplatelet agent? Eur Heart J, 2007; 28: 1717-1722.

49. Tang EW, Wong CK, Herbison P. Global Registry of Acute Coronary Events (GRACE) hospital discharge risk score accurately predicts long-term mortality post acute coronary syndrome. Am Heart J, 2007; 153: 29-35.

50. Ong AT, McFadden EP, Regar E et al. Late angiographic stent thrombosis (LAST) events with drug-eluting stents. J Am Coll Cardiol, 2005; 45: 2088-2092.

51. Bassand J-P. Barking up the right tree at last: Another step closer to a universal definition of bleeding. Eur Heart J, 2014; 35: 1207-1209. doi: 10.193/eurheartj/ehu172.

52. Fiedler KA, Maeng M, Mehilli J et al. Duration of triple therapy in patients requiring oral anticoagulation after drug-eluting stent implantation: The ISAR-TRIPLE trial. J Am Coll Cardiol, 2015; 65: 1619-1629. doi: 10.1016/j.jacc.2015.02.050.

53. Sarafoff N. Duration of triple therapy in patients requiring oral anticoagulation after drug-eluting stent implantation: The ISAR-TRIPLE trial. J Am Coll Cardiol, 2015; 28: 1619-1629. doi: 10.1016/j.jacc.2015.02.050.

54. Dewilde W, Berg JT. Design and rationale of the WOEST trial: What is the optimal antiplatElet and anticoagulant therapy in patients with oral anticoagulation and coronary StenTing (WOEST). Am Heart J, 2009; 158: 713-718.

55. Yusuf S, Zhao F, Mehta SR et al. Effects of clopidogrel in addition to aspirin in patients with acute coronary syndromes without ST-segment elevation. N Engl J Med, 2001; 345: 494-502.
56. Rothberg MB, Celestin C, Fiore LD et al. Warfarin plus aspirin after myocardial infarction or the acute coronary syndrome: Meta-analysis with estimates of risk and benefit. Ann Intern Med, 2005; 143: 241-250.

57. Rubboli A, Halplerin JL, Airaksinen KE et al. Antithrombotic therapy in patients treated with oral anticoagulation undergoing coronary artery stenting. An expert consensus with focus on atrial fibrillation. Ann Med, 2008; 40: 428-436.

58. Sorensen R, Hensen ML, Abildstrom SZ et al. Risk of bleeding in patients with acute myocardial infarction treated with different combinations of aspirin, clopidogrel, and vitamin $\mathrm{K}$ antagonists in Denmark: A retrospective analysis of nationwide registry data. Lancet, 2009; 374: 1967-1974.

59. Hensen ML Sorensen R, Clausen MT et al. Risk of bleeding with single, dual, or triple therapy with warfarin, aspirin, and clopidogrel in patients with atrial fibrillation. Arch Intern Med, 2010; 170: 1433-1441.

60. Mariani M, Mariani G, De Servi S. Efficacy and safety of prasugrel compared with clopidogrel in patients with acute coronary syndromes. Results of TRITON-TIMI 38 trials. Expert Rev Cardiovasc Ther, 2009; 7: 17-23. doi: 10.1586/14779072.7.1.17.

61. Smith PK, Goodnough LT, Levy JH et al. Mortality benefit with prasugrel in the TRITON-TIMI 38 coronary artery bypass grafting cohort. J Am Coll Cardiol, 2012; 60: 388-396. doi: 10.1016/j. jacc.2012.03.030

62. Wallentin L, Becker RC, Budaj A et al. Ticagrelor versus clopidogrel in patients with acute coronary syndromes. N Engl J Med, 2009; 361: 1045-1057.

63. Wiviott SD, Braunwald E, McCabe $\mathrm{CH}$ et al. Prasugrel versus clopidogrel in patients with acute coronary syndromes. N Engl J Med, 2007; 357: 2001-2015.

64. Roe MT, Othman EM. Prasugrel versus clopidogrel for acute coronary syndromes. New Engl J Med, 2013; 368: 188-189.

65. Bonaca MP, Bhatt DL, Cohen M et al. Long-term use of ticagrelor in patients with prior myocardial infarction. New Engl J Med, 2015; 372: 1791-1800.

66. Marciniak TA. FDA secondary review of cancer adverse events and risk benefit. NDA 22-307 prasugrel, 2008. http://www.accessdata.fda.gov/drugsatfda_docs/nda/2009.

67. Marciniak TA. FDA clinical review: Antiplatelet and anticoagulant drugs cancer risk, 2014. http://www.accessdata.fda.gov/drugsatfda_docs/nda/2011/0224330rig1s000MedR.pdf.

68. Unger EF. Weighing benefits and risks: The FDA review of prasugrel. New Engl J Med, 2009; 361: 942-945.

69. Jeger R, Pfisterer M, Alber $\mathrm{H}$ et al. Newest-generation drugeluting and bare-metal stents combined with prasugrel-based antiplatelet therapy in large coronary arteries: The BAsel Stent Kosten Effektivitäts Trial PROspective Validation Examination part II (BASKET-PROVE II) trial design. Am Heart J, 2012; 163: 136-141. doi: 10.1016/j.ahj.2011.08.023.

70. Palmerini T, Biondi-Zoccai G, Della Riva D et al. Stent thrombosis with drug-eluting and bare-metal stents: Evidence from a comprehensive network meta-analysis. Lancet, 2012; 379: 1393-1402.

71. Sarno G, Lagerqvist B, Frobert O et al. Lower risk of stent thrombosis and restenosis with unrestricted use of 'new-generation' drug-eluting stents: A report from the nationwide Swedish Coronary Angiography and Angioplasty Registry (SCAAR). Eur Heart J, 2012; 33: 606-613.

72. Gwon HC, Hahn JY, Park KW et al. Six-month versus 12-month dual antiplatelet therapy after implantation of drug-eluting stents: The efficacy of xience/promus versus cypher to reduce late loss after stenting (EXCELLENT) randomized, multicenter study. Circulation, 2012; 125: 505-513. 
73. Leon MB, Baim DS, Popma JJ et al. A clinical trial comparing three antithrombotic-drug regimens after coronary-artery stenting. Stent Anticoagulation Restenosis Study Investigators. N Engl J Med, 1998; 339: 1665-1671.

74. Abbott's XIENCE PRIMETM and XIENCE Vw drug eluting stents receive indication in Europe for minimum three-month duration of dual anti-platelet therapy.2012. http://www.abbott. com/news-media/pressreleases/abbotts-xience-prime-andxience-v-drug-eluting-stents-receiveindication-in-europe-forminimum-th.htm.

75. Ruiz-Nodar JM, Marin F, Roldan V et al. Should we recommend oral anticoagulation therapy in patients with atrial fibrillation undergoing coronary artery stenting with a high HAS-BLED bleeding risk score? Circulation, 2012; 5: 459-466 .
76. Reddy VY, Holmes D, Doshi SK et al. Safety of Percutaneous Left Atrial Appendage Closure. Results From the Watchman Left Atrial Appendage System for Embolic Protection in Patients With AF (PROTECT AF) clinical trial and the continued access registry. Circulation, 2011; 123: 417-424.

77. Reddy VY, Sievert H, Halperin J et al. Percutaneous left atrial appendage closure vs warfarin for atrial fibrillation: A randomized clinical trial. JAMA, 2014; 312: 1988-1998. doi: 10.1161/CIRCULATIONAHA.110.976449.

78. Camm AJ, Colombo A, Corbucci G et al. Left atrial appendage closure: A new technique for clinical practice. Heart Rhythm, 2014; 11: 514-521.

79. Feixa X, Scalone G, Martín-Yuste V, Vidal B. Large protruding thrombus over left atrial appendage occlusion device successfully treated with apixaban. Eur Heart J, 2015; 36: 1427. 